\title{
The Preparation of Fused Chloride Salts for Use in Pyrochemical Plutonium Recovery Operations at Los Alamos
}

K. W. Fife

D. F. Bowersox

D. C. Christensen

J. D. Williams
LA- -10681

\section{DE86 014881}

\section{DISCLAIMER}

\begin{abstract}
This report was prepared as an account of work sponsored by an agency of the United States Government. Neither the Unitod States Government nor any agency thereof, nur any of their employoes, makes any warranty, express or implied, or assumes any legal liability or responsibility for the accuracy, completeness, or usefulness of any informution, apparatus, product, or process disclosed, or represents that its use would not infringe privately owned rights. Reference herein to any specific commercial product, process, or service by trade name, trademark, manufacturer, or otherwise does not necessarily constitute or imply its endorsement, recommendation, or favoring by the United States Government or any agency thereof. The views and opinions of authors expressed herein do not necessarily state or reflect those of the United States Government or any agency thereof.
\end{abstract}

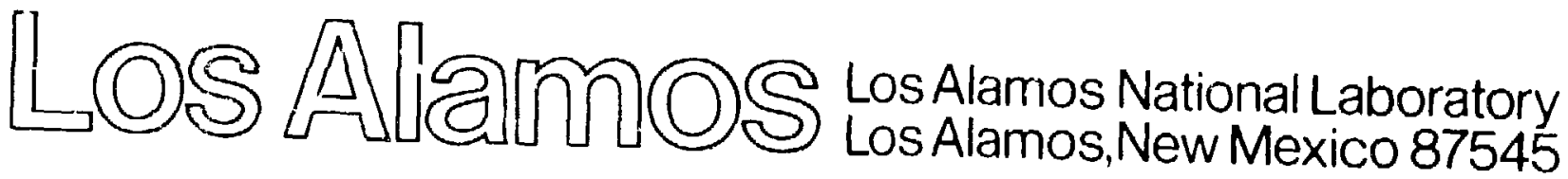




\title{
THE PREPARATION OF FUSED CHLORIDE SALTS FOR USE IN PYROCHEMICAL PLUTONIUM RECOVERY OPERATIONS AT LOS ALAMOS
}

by

\author{
K. W. Fife, D. F. Bowersox, D. C. Christensen, and \\ J. D. Williams
}

\begin{abstract}
The Plutonium Metal Technology Group at Los Alamos routinely uses pyrochemical processes to produce and purify plutonium from impure sources. The basic processes (metal production, metal purification, and residue treatment) involve controlling oxidation and reduction reactions between plutonium and its compounds in molten salts. Current production methods are described, as well as traditional approaches and recent developments in the preparation of solvent salts for electrorefining, molten salt extraction, lean metal (pyroredox) purification, and direct oxide reduction.
\end{abstract}

\section{PLETONILM PYROCHF.MISTRY AT LOS MLAMOS}

The Plitunium Metal Technology Ciroup (MST-13) routirely recovers purc plu'onium metal from impurc sciap sourees using chemical or electrochemical oxidation and reduction reactions in molien chloride solvent sillts.

Each of these batcli pyrochemical operations requires. a unique salt matrix that can act as reaction media, a reactant, or a solvent for impurities. The volume of salt for each of the batch operations is large, relative to the amount of plttonium in the process, and the quality of the feed salts is extrencly important. Measures of quality include moisture content, oxygen content, and the concentration of elemental impuritics. Low-quality salts result in low process yiclds. low product quality, and incrcased operational costs.

This report summarizes the preparation recuirements for reagent- and food-grade salts used in plutonium metal production at Los Alamos. We first discuss the major metal production steps and the role of each salt in those steps. We then describe salt preparation; and finally. we discuss our development efforts for improved salt preparation.

\section{PLUTONIUMI METAL PRODUCTION, PURIFICATION, AND RESIDUE TREATMENI}

The pyrochemical opcrations at Los Alamos can be broken down into three basic eategories-metal production, metal purification, and residue treatment. Figure $l$ is a flow diagram of the various process steps. The following paragraphs discuss these steps and the roles of salt reagents.

\section{A. Metal Production}

Two major metal production operations are tised to convert $\mathrm{PuO}_{2}$ to plutonium metal-the classical bomb reduction, or $\mathrm{PuF}_{4}$ reduction step, ${ }^{1-5}$ and the direct reduction of $\mathrm{PuO}_{2}$ to metal. ${ }^{1.2 .5}$ Both processes consist of chemically reducing plutonium compounds to plutonium metal with no purification of the metal occurring.

In $\mathrm{PuF}_{4}$ reduction, $\mathrm{PuO}_{2}$ is first fluorinated with $\mathrm{HF}$ to $\mathrm{PuF}_{4}$. This compound is mixed with iodine and calcium metal, thew heated in an induction furnace to initiate the reactions. Both the iodine and $\mathrm{PuF}_{4}$ reactions with calcium are very exothermic: the waste slag $\left(\mathrm{CaI}_{2}\right.$ and $\left.\mathrm{CaF}_{2}\right)$ melts, allowing the plutonium metal to 


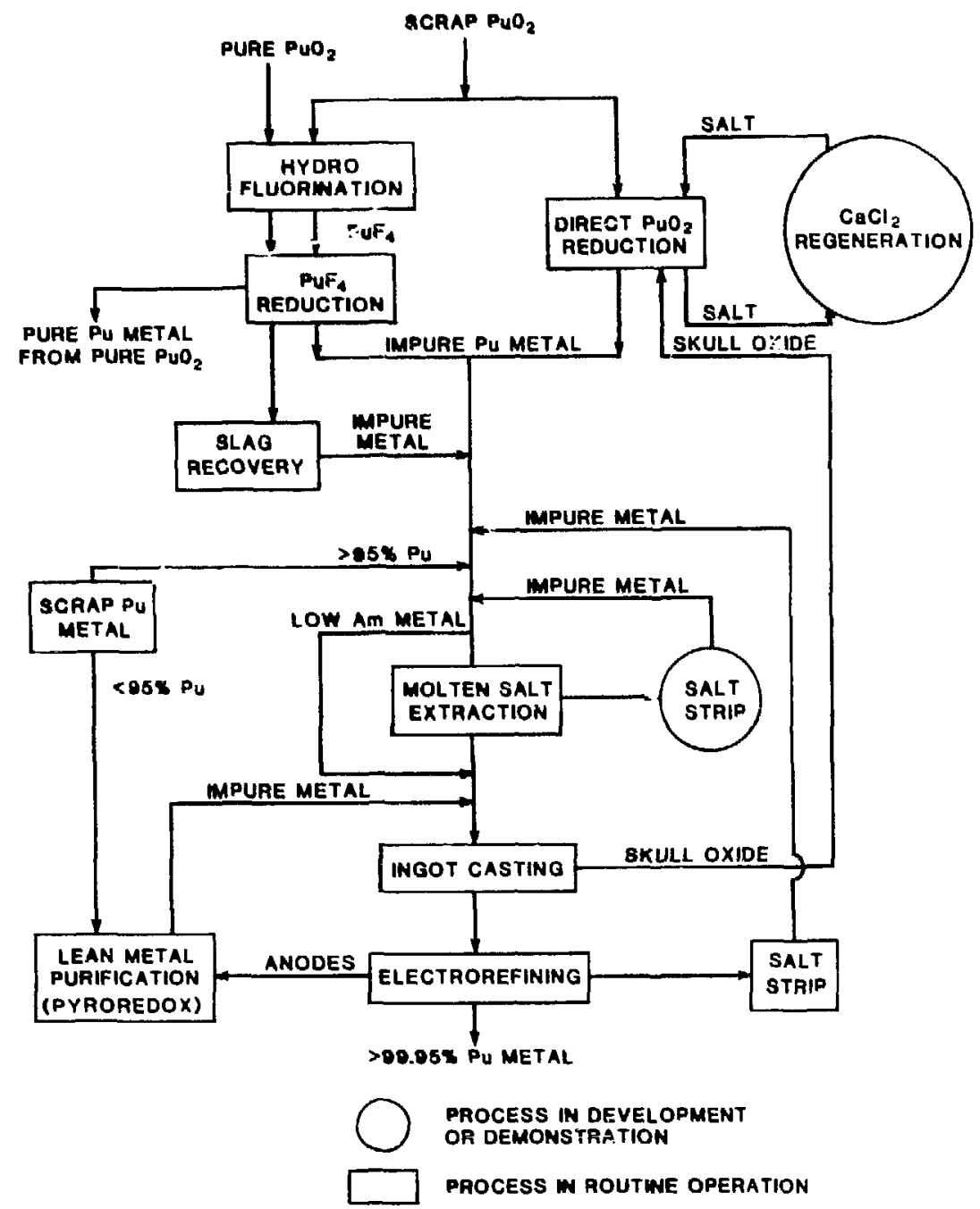

Fig. 1. Plutonium pyrochemical operations at Los Alamos.

coalesce in the bottom of the ceramic reaction vessel. Metal yields from this process normally exceed $98 \%$.

Direct oxide reduction (DOR) converts $\mathrm{PuO}_{2}$ to metal by reduction with calcium metal in a $\mathrm{CaCl}_{2}$ solvent salt. The molten $\mathrm{CaCl}_{2}$ not only acts as a heat sink during the exothermic reduction reaction and provides a medium in which to mix the reactants, it also dissolves the $\mathrm{CaO}$ by-product to $18 \mathrm{~mol} \%$ ( $10 \mathrm{wt} \%$ ), which aids in product metal coalescence. Metal yields from this process normally exceed $95 \%$.

\section{B. Metal Purfication}

Our purification process has two principal steps-molten salt extracticn (MSE) ${ }^{1,6}$ and electrorefining (ER) ${ }^{1,7-9}$ In the MSE step americium is removed by contacting molten plutonium metal with a molten oxidizing salt $\left(\mathrm{MgCl}_{2} \cdot \mathrm{KCl} \cdot \mathrm{NaCl}\right){ }^{*}$ The $\mathrm{MgCl}_{2}$ oxidizes americium and some plutonium into the salt phase, purifying the plutonium but with some loss. If the impure metal produced in either DOR or $\mathrm{PuF}_{4}$ reduction contains $>1000 \mathrm{ppm} \mathrm{Am}$, the metal is sent through MSE. If the metal contains $<1000 \mathrm{ppm}$ americium, it bypasses MSE and proceeds to ingot casting.

Ingot casting is essentially a sizing operation to produce metal ingots for feed in to electrorefining. Although the casting operation is performed under vacuum and some volatiles $\left(\mathrm{Ca}^{\circ}, \mathrm{Mg}^{\circ}\right)$ are removed, it is not a true purification step.

Electrorefining is the main purification process performed at Los Alamos. It can produce kilogram

\footnotetext{
${ }^{241} \mathrm{Pu}$ decays to ${ }^{241} \mathrm{Am}$ at the rate of approximately $41 \mathrm{ppm} / \mathrm{month} / \mathrm{at} . \%{ }^{241} \mathrm{Pu}$.
} 
quantities of plutontum metal with purity regularly excecding $99.95 \%$. The impure plutonium feed is slightly oxidized in an $\mathrm{MgCl} \cdot \mathrm{NaCl} \cdot \mathrm{KCl}$ electrolyte to charge the solvent with $\mathrm{Pu}^{\prime}$. During clectrorefining plutonium is preferentially ovdised at an impure anode surface. From the anode. plutonium migrates through the solvent salt and is reduced at a separate cathode surface. As plutonium is depleted from the anode, impurities more electropositive than plutonium concentrate and eventually form solid plutonium alloss, inhobiting lurther axidation of the plutonium. If not controlled, these impure alloys begin to on idiec instead of plutonium. We control the umwanted oxidation of inipurties by periodically moniloring the open circuit polential or back-comt of the cell during the process. The process termonalles when this potential increases to a predetermaned ialue. Metal thelds from clectrorctining are normally 7(1)-850 with $111-1.5 \%$ of the feed plutenium remanns. in the anocke. The remainder of the plute-

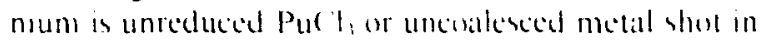
the salt phatse

\section{Residue Treatment}

Residues from DOR and $\mathrm{PuF}_{4}$ reduction are mainly salts $\left(\mathrm{CaCl}_{2} \cdot \mathrm{CaO}\right.$ or $\left(\mathrm{aF}_{2} \cdot \mathrm{Cal}_{2}\right)$ that occasionally contain enough uncoalesced or unreduced plutonium to justify pyrochemical reprocessing. The DOR salts may be reprocessed by adding ( $\mathrm{aCl}$, to dilute the $\mathrm{CaO}$, and calcium metal to provide a reducing environment. We are currently demonstrating al regeneration technique for spent DOR salts that rechlorinates the $\mathrm{CaO}$ byproduct and produces a $\mathrm{CaC} \mathrm{I}_{2}$ salt suitable for recycle to DOR. ${ }^{10}$

Plutonium may be effectively recovered from $\mathrm{PuF}_{4}$ reduction slag by similar reprocessing "in which $\mathrm{CaCl}_{2}$ is added to the erushed $\mathrm{CaF}_{2} \cdot \mathrm{C}_{2}$ slag to lower its melting point from $13200^{\circ} \mathrm{C}$ to $800^{\circ} \mathrm{C}$. As with the DOR salts, calciun metal is ad a to provide a reducing environment.

Residues from MSE contain significant quantities of plutonian $(100-200$ s) that are co-oxidized with americium. Wecan recover the oxidized plutonium and americium by reduction with ealcium metal, but have yet to develop a suitable pyrochemical technique for separating the two metals. Current research is focusing on both chemical ${ }^{12}$ and electrochemical ${ }^{13}$ separation techniques.

The electrerefining operation produces more residue than any other aspect of plutonium pyrochemistry. In addition to producing pure plutonium. electrorefining also generales rich waste salts and spent anodes. These salts are currently treated similarly to spent MSE salts ${ }^{14}$ by reduction with cialciuns metal. The spent anodes, however, require a more complex pyroredox process ${ }^{15}$ to separate the plutonium from the concentrated impurities. This process consists of selectively oxidizing plutonium with $\mathrm{ZnCl}$ in a $\mathrm{KC} / \mathrm{l}$ diluent. The zinc and impuritics more electropositive than zime collect during plutonium oxiclation. The $K_{3} P u C l_{6}$ salt phase is then mechanically separated from the zine metal residue and reduced with calcium metal in a DOR-like step. The metal from this step contains a mixture of plutonium. calcium, and zine from which the plutonium is separated by gravity. This plutonium concentrate is then suitable for electrorefining.

From this cursory overview of our pyrochemical operations, we see that large volunres and varieties of high-quality chloride-based solvent salts are required for plutonium metal production. Table I summarizes the salt requirements for the various pyrochemical processes.

Moist salts are detrimental because oxide formation adversely affects metal coalescence and recovery. Gross element impurities in the salts are detrimental because molten plutonium metal very effectively scavenges them, ultimately reducing electrorefining yields. Therefore, the reagent- or food-grade salts used in our

\begin{tabular}{|c|c|}
\hline Process & Required Salt \\
\hline PuF $\downarrow$ reduction & - No added salt; it is generated in situ \\
\hline DOR & $-\mathrm{CaCl}_{2}$ \\
\hline MSE & $\begin{array}{r}-\mathrm{KCl} \cdot \mathrm{NaCl} \cdot \mathrm{MgCl}_{2} \text { or } \\
\mathrm{CaCl}_{2} \cdot \mathrm{NaCl} \cdot \mathrm{MgCl}_{2}\end{array}$ \\
\hline Ingot casting & - no added salt \\
\hline Electrorefining & $-\mathrm{KCl} \cdot \mathrm{NaCl} \cdot \mathrm{MgCl}_{2}$ \\
\hline $\mathrm{PuF}_{4}$ slag recovery & $-\mathrm{CaCl}_{2}$ \\
\hline MSE salt strip & - Possibly $\mathrm{CaCl}_{2}$ \\
\hline Electrorefining salt strip & - Possibly $\mathrm{CaCl}_{2}$ \\
\hline Pyroredox & $-\mathrm{CaCl}_{2}$ and $\mathrm{ZnCl} \cdot \mathrm{KCl}$ \\
\hline
\end{tabular}


nvrochemical operations must be treated before use. Section III describes the treatment processes.

\section{SALT PREPARATION}

The goal of our pyrochemical operations is to recover and purify plutonium metal from impure feed streams. These operations require such large volumes of feed salts that we cannot justify the time or effort necessary to produce polarographic-grade salts (no water, water by-products, or metallic impurities). Although timeconsuming and complex, there are established physical, chemical, and electrochemical techniques to produce polarographic salts suitable for electrochemical research. ${ }^{16-20}$

Before 1983, plutonium feed streams at Los Alamos were well characterized and high quality. We enjoyed good process yields with minimal residue generation. Food-grade or reagent-grade salt preparation consisted of drying in vacuum ovens to dehydrate bulk hygroscopic salis $\left(\mathrm{CaCl}_{2}\right)$ and/or storing the salts under argon until used $\left(\mathrm{KCl}, \mathrm{NaCl}, \mathrm{MgCl}_{2}\right) . \mathrm{CaCl}_{2}$, used in DOR and salt stripping operations, was pressed into cylinders after drying to minimize the surface area-tovolume ratio for moisture absorption and also to increase its density, which simplified loading the salt into the processes.

Since 1983, however, pyroredox processing, which requires special preparation of the binary salt $\mathrm{ZnCl}_{2} \cdot \mathrm{KCl}$, has been integrated into the recc.ery scheme. Also, feed $\mathrm{PuO}_{2}$ for the DOR process has become more variable, is generally not well characterized, and is of lower quality. As a result, more care is required in preparing the $\mathrm{CaCl}_{3}$; impurities (water or water by-products) affect the reduction reaction. the subsequent product metal coalescence, and ultimately, the process vield. The following sections describe the available salt preparation techniques and their effects on plutonium metal processing.

\section{A. Electrorefining Salts}

This process uses an equimolar mixture of $\mathrm{NaCl}$ and $\mathrm{KCl}$ as the solvent salt. Both of these salts are purchased as reagent-grade materials from a variety of chemical supply houses. They are not appreciably hygroscopic and are fused before use in electrorefining. Before fusing, the undried, as-received salts are mixed and placed in a quartz or platinum crucible. The salts and crucible are then placed in a stainless steel furnace tube, backfilled with purified argon, and resistance-heated to $750-800^{\circ} \mathrm{C}$. After fusing, the mixture is cooled, removed from the crucible, and stored in a vacuum oven at $200^{\circ} \mathrm{C}$ until needed. This simple procedure allows production of these salts on a demand basis. These salts provide trouble-free performance in the electrorefining operation. As the salts are loaded into an electrorefining run. 75 to $100 \mathrm{~g}$ of $\mathrm{MgCl}_{2}$ are added as loose salt to oxidize plutonium and charge the electrolyte with $\mathrm{Pu}^{+3}$.

\section{B. Molten Salt Extraction (MSE) Salts}

MSE uses fused equimolar $\mathrm{NaCl} \cdot \mathrm{KCl}$ (from $\mathrm{ER}$ salt production) with the addition of 300 to $500 \mathrm{~g}$ of loose $\mathrm{MgCl}_{2}$. The $\mathrm{MgCl}_{2}$ is purchased from the Titanium Corporation of America and although the salt is hygroscopic, the only ireatment is storage in glass containers to keep out excess moisture. No problems with metai recoveries or oxidation yields in MSE have been observed as a result of this minimal procedure.

To simplify and optimize MSE, the established feed salt $\left(\mathrm{NaCl} \cdot \mathrm{KCl} \cdot \mathrm{MgCl}_{2}\right)$ and an alternate salt mixturc $\left(\mathrm{CaCl}_{2} \cdot \mathrm{KCl} \cdot \mathrm{MgCl}_{2}\right)$ were separately fused in a process similar to that used for ER salts. The salts performed well, but because we do not routinely perform MSE, production of ternary salts was not adopted for the process.

The procedure for preparing the salt mixture entailed blending the three salts in an inert box and transferring them to a platinum or quartz crucible for fusing. The mixture was melted, sparged with argon to mix the components, vacuum-transferred, ${ }^{*}$ and cast into a quartz mold where it cooled under argon. The quality of thise two ternary fused salt mixtures are described in Table II.

\section{Lean Metal Purification or Pyroredox Salts}

Until the development of pyroredox (lean metal) purification, salt preparation for all pyrochemical processes was relatively simple. However, the $\mathrm{ZnCl}_{2}$ used for upgrading lean metal residues is hygroscopic to the point of being deliquescent, and special handling procedures are necessary. Moisture is detrimental to pyrochemical operations, and the necessary operating temperature $\left(800^{\circ} \mathrm{C}\right)$ for the pyroredox oxidation step is above the boiling point of $\mathrm{ZnCl}_{2}\left(732^{\circ} \mathrm{C}\right)$. For these reasons, we mixed the $\mathrm{ZnCl}_{2}$ with $\mathrm{KCl}$ to form a eutectic composition $\left(\mathrm{KCl} \cdot 45.1 \mathrm{wt} \% \mathrm{ZnCl}_{2}\right)$, which is much less hygrosopic than pure $\mathrm{ZnCl}_{2}$ and is stable at temperatures $>800^{\circ} \mathrm{C}$.

Preparation of this salt was complicated by its high affinity for water and the large volume needed for process demonstration. The established procedure was to sparge a batch of the predried molten salt mixture

\footnotetext{
*Vacuum-transfer will be discussed in more detail in the sections describing fused pyroredox and fused $\mathrm{CaCl}_{2}$ production.
} 


\begin{tabular}{|c|c|c|}
\hline Impurity & $\begin{array}{c}\mathrm{NaCl} \cdot \mathrm{KCl} \cdot \mathrm{MgCl}_{2} \mathrm{~b} \\
(\mathrm{ppm} \text { or } \mathrm{wt} \%)\end{array}$ & $\begin{array}{c}\mathrm{CaCl}_{2} \cdot \mathrm{KCl} \cdot \mathrm{MgCl}_{2}{ }^{\mathrm{C}} \\
(\mathrm{ppm} \text { or wt\%) }\end{array}$ \\
\hline Alkalinity & 0.23 wt $\%$ & 0.24 wt $\%$ \\
\hline $\mathbf{A g}$ & $<\mathbf{1}$ & $<1$ \\
\hline Al & 9 & 14 \\
\hline $\mathbf{B}$ & 4 & 8 \\
\hline $\mathbf{B a}$ & 6 & 3 \\
\hline Be & $\because$ & $<1$ \\
\hline $\mathrm{Bi}$ & $<3$ & $<10$ \\
\hline $\mathrm{Ca}$ & 300 & Major \\
\hline Cd & $<10$ & $<10$ \\
\hline $\mathrm{Ce}$ & $<30$ & $<30$ \\
\hline $\mathrm{CO}_{3}$ & 10 & $<10$ \\
\hline Co & $<3$ & $<3$ \\
\hline $\mathrm{Cr}$ & $<3$ & $<3$ \\
\hline $\mathrm{Cu}$ & $<1$ & $<1$ \\
\hline $\mathrm{Fe}$ & 14 & 14 \\
\hline Ga & $<3$ & $<3$ \\
\hline $\mathrm{H}_{2} \mathrm{O}$ & $0.22 \times \mathrm{t}^{\%} \%$ & $0.21 \times t^{0} \%$ \\
\hline Hf & $<300$ & $<120$ \\
\hline $\mathbf{K}$ & Major & Major \\
\hline La & $<10$ & $<\mathbf{1 0}$ \\
\hline Li & $<3$ & $<\mathbf{5 0}$ \\
\hline $\mathrm{Mg}$ & Major & Major \\
\hline Mn & $<3$ & $<1$ \\
\hline Mo & 3 & $<10$ \\
\hline $\mathrm{Va}$ & Major & 565 \\
\hline Nb & $<30$ & $<30$ \\
\hline $\mathrm{Ni}$ & 11 & $<10$ \\
\hline Total oxygend & $0.22 \times t^{13 /}$ & $0.25 \times 1 \%$ \\
\hline $\mathbf{P b}$ & $<10$ & $<10$ \\
\hline Pt & $<30$ & $<10$ \\
\hline $\mathbf{R b}$ & $<100$ & $<80$ \\
\hline $\mathbf{R e}$ & $<30$ & $<\mathbf{3 0}$ \\
\hline $\mathbf{S i}$ & $<30$ & $<\mathbf{3 0}$ \\
\hline Sn & $<10$ & $<10$ \\
\hline Sr & $<5$ & 0.1 to $1.0 \mathrm{wt} \%$ \\
\hline Ta & $<300$ & $<300$ \\
\hline Ti & $<10$ & $<10$ \\
\hline $\mathbf{V}$ & $<3$ & $<3$ \\
\hline w & $<100$ & $<100$ \\
\hline Y & $<\mathbf{3}$ & $<3$ \\
\hline Zn & $<30$ & $<100$ \\
\hline $\mathrm{Zr}$ & $<10$ & $<10$ \\
\hline \multicolumn{3}{|c|}{ 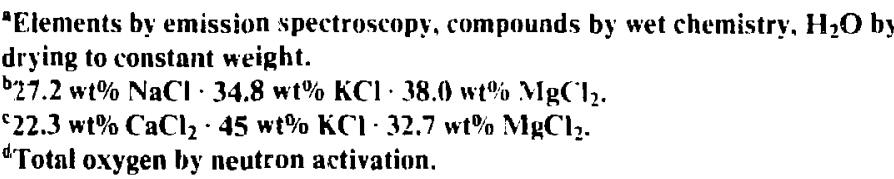 } \\
\hline
\end{tabular}


with anhydrous $\mathrm{HCl}$ for 4 to $5 \mathrm{~h}$ and then vacuum-filter the melt into a sacrificial pyrex assembly that was later broken away to recover the salt (Fig. 2). This procedure was time-consuming and required many furnace runs per week to meet the demand. We conducted experimients to reduce the gas contact time and to increase the rarducion per furnace run.

The $\mathrm{HCl}$ condit wning and filtration removed water and impurities and converted metallic oxides to chlorides. When melted, the $\mathrm{ZnCl}_{2} \cdot \mathrm{KCl}$ mixture is opaque, viscous, and does not readily filter. The adi:tion of $\mathrm{HCl}$ to the melt improves the color and viscosity, allowing filtration. We suspect certain hydrolysis reactions are riversed during the conditioning and that nerallic chlorides are formed, precipitated, and removed by filtration. Table III lists impurity levels in filtered product salts; Fig. 3 is a photograph of the filter cake collected after a production run.

Our first experirnental objective was to minimize the 4- to 5-h gas contact time. Figure 4 illustrates that total oxygen and water content of the salt varies only slightly $(0.08 \mathrm{wt} \%$ to about $0.05 \mathrm{wt} \%)$ after $3 \mathrm{~h}$ of $\mathrm{HCl}$ contact. This decrease did not appear to justify a full 5 -h gas contact time.

All off gas from the fusing operation is routed through caustic scrubbers for $\mathrm{HCl}$ neutralization before venting to the atmosphere. For several runs, we monitored the $\mathrm{pH}$ of the lead scrubber (Fig. 5) and compared these profiles with profiles generated from straight neutralization of scrubber solution with $\mathrm{HCl}$ (Fig. 6). The profiles fall into the same region after approximately $2 \mathrm{~h}$, in- dicating $\mathrm{HCl}$ consumption is complete early in the process and $5 \mathrm{~h}$ of $\mathrm{HCl}$ treatment is excessive. These data and the data shown in Fig. 4 indicated that a reduction in $\mathrm{HCl}$ contact time would not affect product salt quality.

In conjunction with reducing contact time, we were also interested in increasing salt production by removing the molten salt from the vessel after $\mathrm{HCl}$ conditioning. Removing the salt would allow us to add fresh salt to an already prcheated vessel. We accomplished this by vacuum-transferring the salt from the hot vessel to an ambient-temperature mold where it could cool under argon. Figuie 7 illustrates the two transfer techniques we considered: pressure-assist and vacuum-assist. We chose vacuum-transfer because of its inherent safety. A leak in a pressurized system may spray salt or rupture a vessel: if a leak develops during vacuum-transfer, vacuum is lost and no movement of salt occurs.

The semicontinuous vacuum-transfer apparatus we developed (Figs. 8 and 9) replaced the original system shown in Fig. 2. The new system provides $\mathrm{HCl}$ conditioning and filtration, as well as vacuum-transfer and chill-casting of the salt product. The new system triples the salt production of the original batch process without affecting salt quality. Unlike the batch apparatus of Fig. 2 , the new system components are reusable. The only major change is the use of a coarse-porosity filter rather than medium-porosity filter. This change keeps the liquid velocity sufficiently high in the transfer tube to minimize plugging. If plugging does occur, the binary salt is readily soluble in water, enabling easy cleaning.

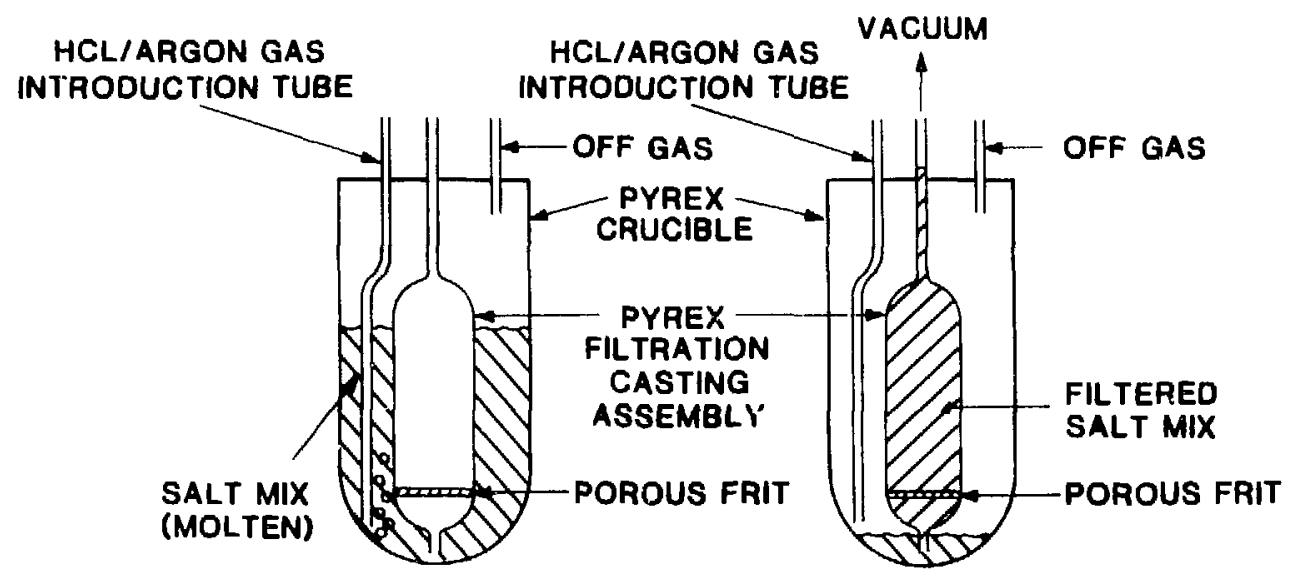

(a) BEFORE FILTRATION

(b) AFTER FILTRATION

Fig. 2. Batch pyroredox salt production apparatus. 


\begin{tabular}{|c|c|c|c|}
\hline Impuring & $\begin{array}{c}\text { I'nfiltered } \\
\text { (ppm or w:(\%) }\end{array}$ & $\begin{array}{c}\text { Filtered } \\
\text { (ppm or w1\%) }\end{array}$ & $\begin{array}{c}\text { Filter Cake } \\
\text { (ppm or at\%) }\end{array}$ \\
\hline Ag & $<1$ & $<5$ & $<1$ \\
\hline Al & $<20$ & $<20$ & $800-1000$ \\
\hline E & $<10$ & $<10$ & $50-60$ \\
\hline Ba & $<30$ & $<30$ & $25-100$ \\
\hline Be & $<2$ & $<2$ & $<1$ \\
\hline $\mathbf{B i}$ & $<5$ & $<10$ & $<10$ \\
\hline $\mathrm{CO}_{3}$ & $<10$ & $<10$ & $<10$ \\
\hline $\mathrm{Ca}_{\mathrm{n}}$ & 100 & $<100$ & $200-300$ \\
\hline Cd & $<5$ & $<10$ & $<10$ \\
\hline $\mathrm{Ce}$ & $<10$ & $<10$ & $<10$ \\
\hline Co & $<5$ & $<3$ & $<3$ \\
\hline $\mathrm{Cr}$ & $<5$ & $<5$ & $4-25$ \\
\hline Cs & $<100$ & $<100$ & $<100$ \\
\hline $\mathrm{Cu}$ & $<5$ & $1-2$ & $<1$ \\
\hline $\mathrm{Fe}$ & $<20$ & $<25$ & $<20$ \\
\hline $\mathrm{H}_{2} \mathrm{O}$ & $0.2 w t^{0} \%$ & $0.1+1 \%$ & $0.1 \mathrm{wr} \%$ \\
\hline Hi & $<150$ & $<100$ & $<180$ \\
\hline LA & $<15$ & $<10$ & $<10$ \\
\hline $\mathrm{Li}$ & $<5$ & $<5$ & $<5$ \\
\hline $\mathbf{M g}$ & $<10$ & $<25$ & $30-200$ \\
\hline Mn & $<3$ & $<.3$ & 6 \\
\hline Mo & $<5$ & $<3$ & $<3$ \\
\hline $\mathrm{Na}$ & $<15$ & $<15$ & $70-100$ \\
\hline $\mathrm{Nb}$ & $<30$ & $<30$ & $<30$ \\
\hline $\mathrm{Ni}$ & $<5$ & $<3$ & $<3$ \\
\hline Total oxygen" & $0.06 w t \%$ & $0.06 w+\%$ & - \\
\hline $\mathbf{P b}$ & $<7$ & $<3$ & $<3$ \\
\hline $\mathbf{R b}$ & $<75$ & $<50$ & $<100$ \\
\hline $\mathbf{R e}$ & $<15$ & $<30$ & $<30$ \\
\hline Se & $<60$ & $<60$ & $<60$ \\
\hline $\mathbf{S i}$ & $<15$ & $<20$ & $1000-1500$ \\
\hline$S_{n}$ & $<5$ & $<5$ & $<5$ \\
\hline Sr & $<5$ & $1-2$ & $<2$ \\
\hline $\mathbf{T a}$ & $<150$ & $<100$ & $<100$ \\
\hline $\mathrm{Ti}$ & $<5$ & $<5$ & $<3$ \\
\hline 1 & $<5$ & $<3$ & $<3$ \\
\hline $\mathbf{w}$ & $<150$ & $<\mathbf{1 0 0}$ & $<100$ \\
\hline r & $<5$ & $<3$ & $<3$ \\
\hline $\mathbf{Z}_{\mathbf{r}}$ & $<15$ & $<10$ & $<10$ \\
\hline
\end{tabular}

Elements by emission spectroscopy, compounds by wet chemistry, $\mathrm{H}_{2} \mathrm{O}$ by drying to constant weight.

Total oxygen by neutron activation.

\section{Direct Oxide Reduction Salt}

The DOR processing step and the other residue treatmient operations use $\mathrm{CaCl}_{2}$ as a diluent or a sclvent salt. The demand for this common salt far exceeds other salts. Befor 1084, we preparud $\mathrm{CaCl}_{2}$ by drying the asreceived salt (Mallinckrodt or Americium International (hemical food-grade) in a vacuum oven for 5 to 7 days at $100^{\circ} \mathrm{C}$. folluwed by 5 to 7 days at $225 \mathrm{C}$. This trying was necessary to remove absorbed moisture from the hygroscopic salt and to prevent unwanted hydrolysis reactions of the form $\mathrm{CaCl}_{2}+\mathrm{H}_{2} \mathrm{O} \leftrightarrows \mathrm{CaO}+2 \mathrm{HCl}$. After drying, we split the salt into $5-\mathrm{kg}$ increments, then sealed them by double-bagging in polyvinylchloride bags. This bagged salt was then sent to another Los Alamos facility for isostatic pressing into cylinders. The pressing provided volume reduction, which eased handling, minimized surface area, and provided the correct shape for loading into DOR. After pressing, we removed the plastic bags and stored the salts in yacuum ovens until needed.

This procedure was successful from a DOR processing standpoint but had disadvantages. Among them was the potential for carbon contamination from the plasticizer in the plastic bags. Figure 10 shows photographs of typical pressed salts just before use in DOR. The black surface contamination is thought to be carbon, which cannot be determined in $\mathrm{CaCl}_{2}$ by current analytical techniques. Carbon is difficult to remove from plutonium by pyrochemistry because low carbon concentrations form high-melting $\mathrm{p}^{\prime}$ เtonium carbide.

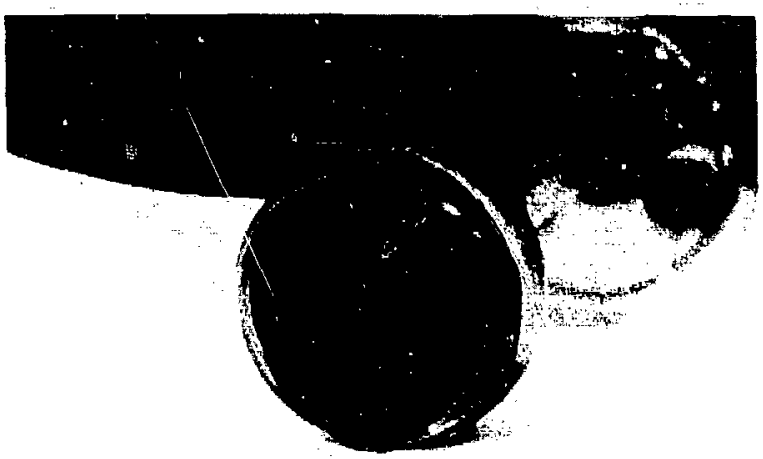

Fig. 3. Filter apparatus with filter cake from pyroredox salt production. 

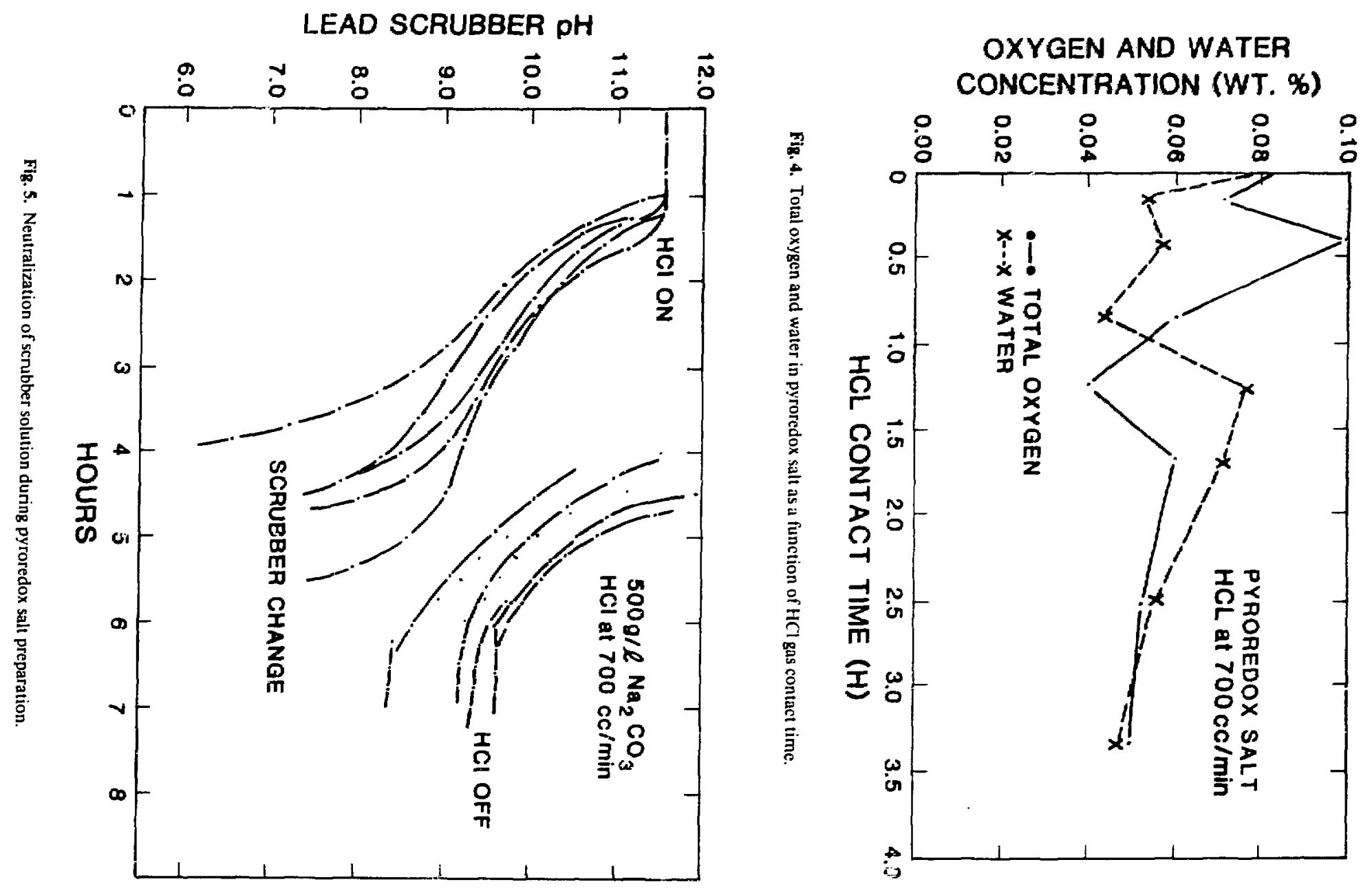


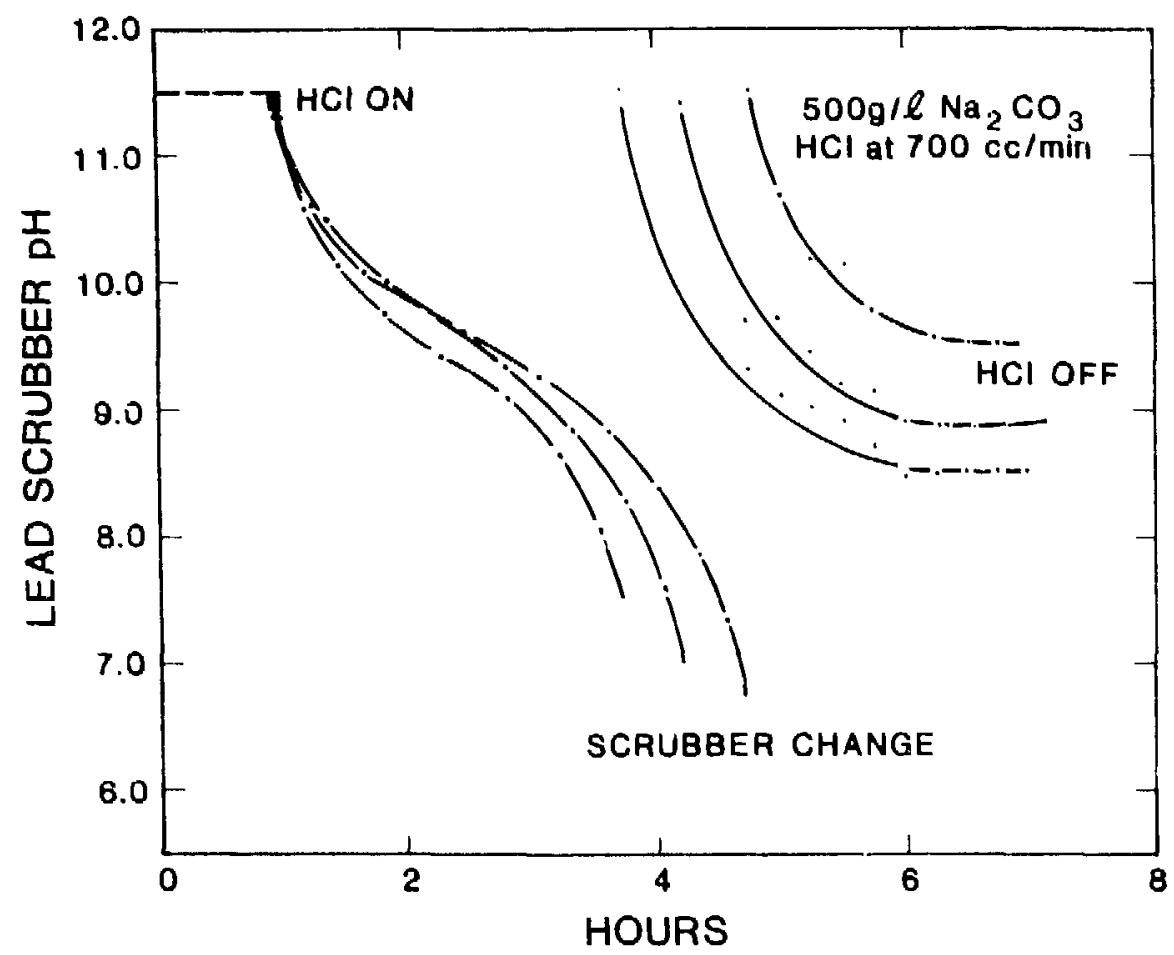

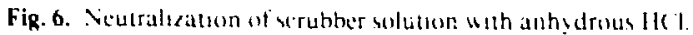

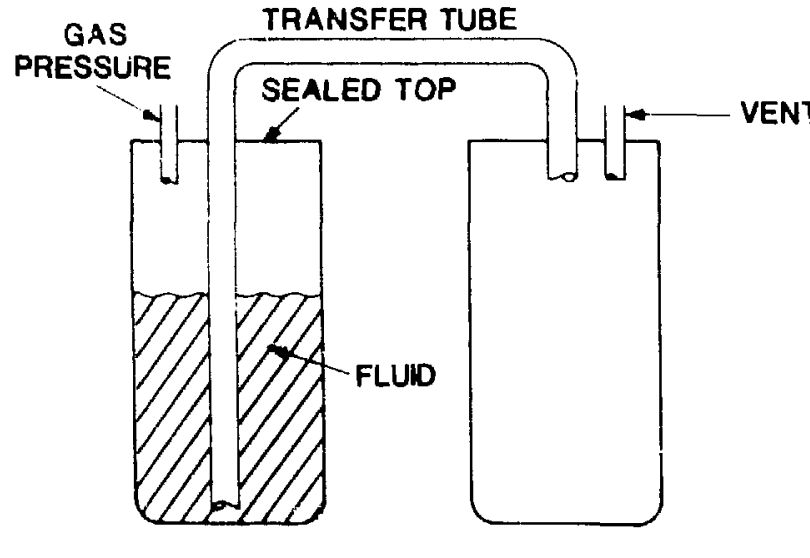

HOLDING VESSEL RECEIVING VESSEL (A) PRESSURE-ASSIST FLUID TRANSFER

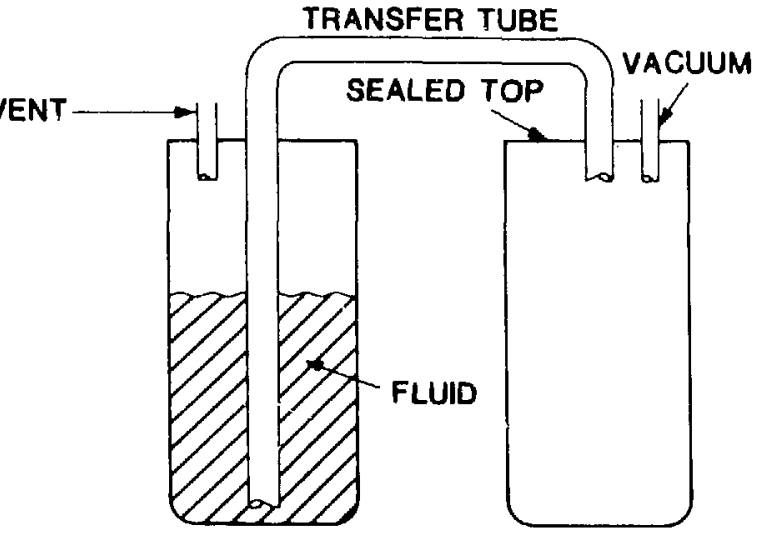

HOLDING VESSEL RECEIVING VESSEL (B) VACUUM-ASSIST FLUID TRANSFER

Fig. 7. Schematic of pressure-assist and vacuum-assist fluid transfer. 


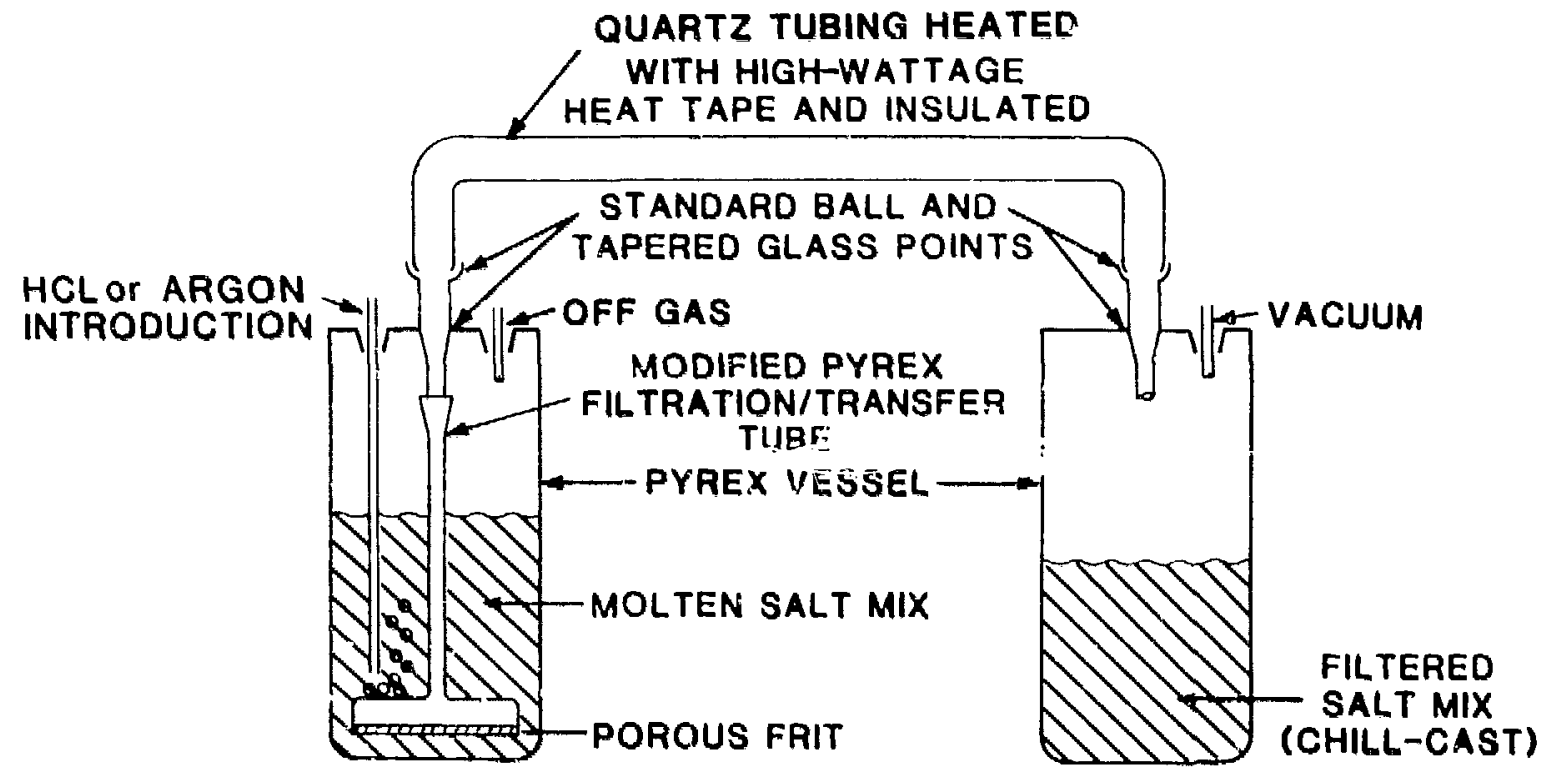

Fig. 8. Apparatus used in semicontinuous pyroredox salt preparation.

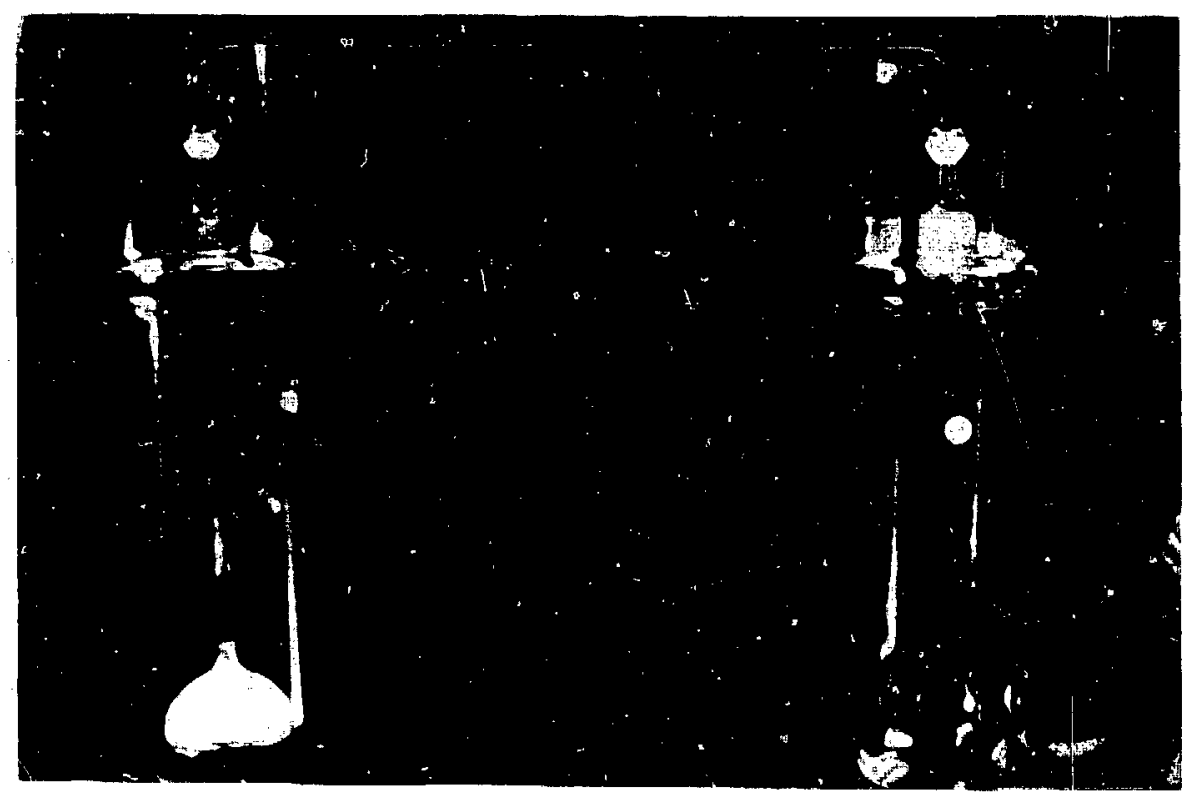

Fig. 9. Production apparatus for use in continuous filtcring, transferring, and casting pyroredox salts. 

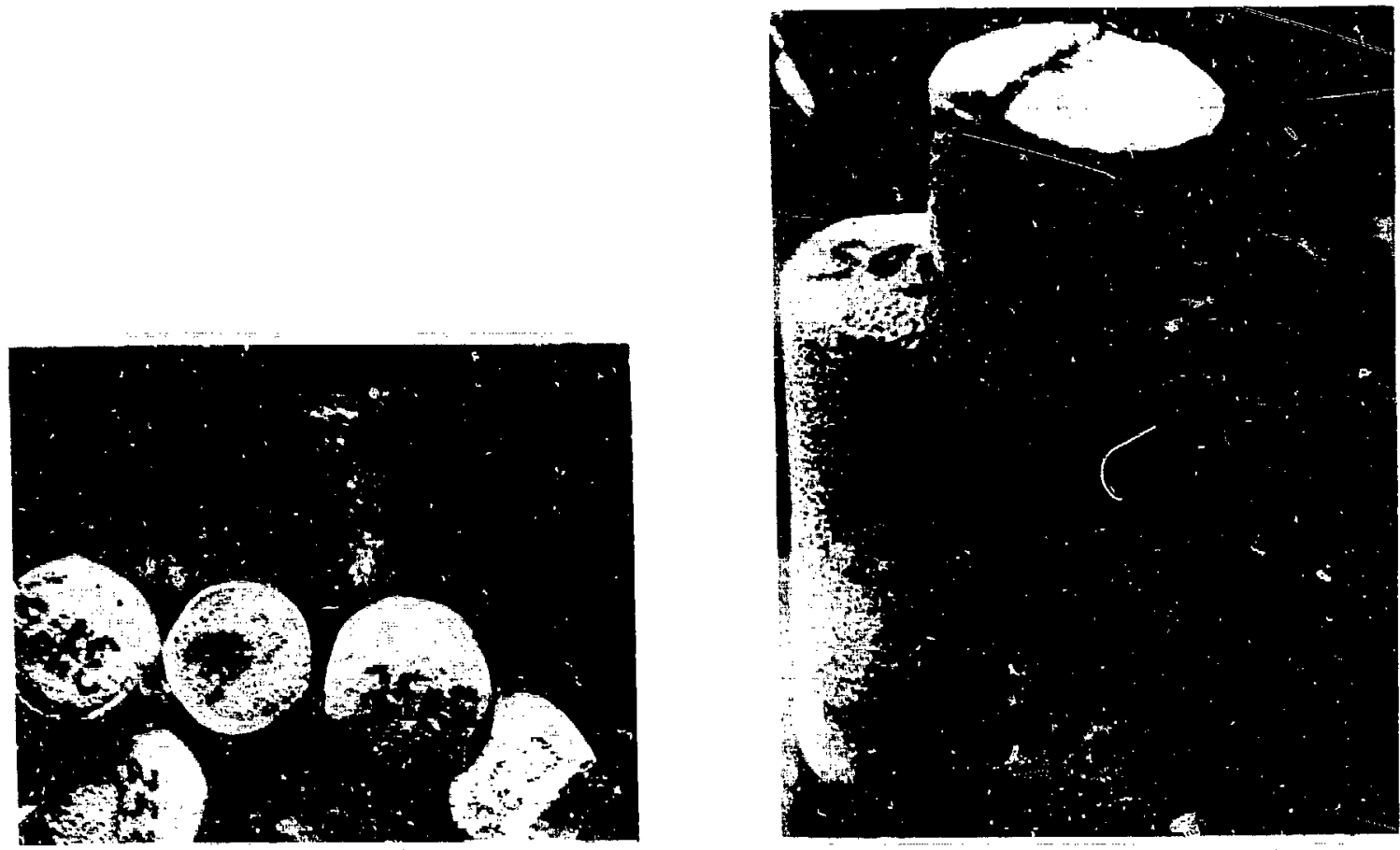

Fig, 10. Pressed $\mathrm{CaCl}_{2}$ before urs in DOR showing probable carbon contamination from plasticizer.

We warted to inprove processing econonics and product availability by performing $\mathrm{CaCl}_{2}$ preparation in-house. In-house preparation would allow us to minimize the carbon and total oxygen content of the salt (total oxygen is determined by neutron activation and includes all oxy-species in the salt). In the DOR reaction. calcium metal is consumed by oxy-species and forms $\mathrm{CaO}$. which could oversaturate the solvent. Oversaturation hinders plutonium metal coalescence due to salt density and viscosity increases, which reduce process yields.

We found that by fusing and casting the $\mathrm{CaCl}_{2}$, we could better control the geometry, further minimize the surface area for moisture absorption, eliminate carbon contamination from plasticizers, better respond to changes in salt demand, and also provide some pretreatment to the salt for the removal of water and oxyspecies.

Since we had developed vacuum-transfer for the production of pyroredox salts, it was logical to apply the technique to the production of fused $\mathrm{CaCl}_{2}$. Because $\mathrm{CaCl}_{2}$ expands as it freezes, we cast the salt into split molds. Originally, the cylindrical molds were constructed from 316 stainless steel with 3/8- to 1/2-inchthick walls. coated with either erbia or yttria to passivate the steel surface. $T r_{i}$ is preparation was normally good for 50 to 75 castings before the metal began to show. We now use aluminum molds (alloy 6061) with 1/2-inchthick walls. Aluminam molds are lighter, cheaper, provide better neat transfer characteristics, do not contaminate the salt, and have a lifetime of about 200 castings. We are currently evaluating various grades and thicknesses to determine the best mold material.

The procedure for fusing $\mathrm{CaCl}_{2}$ consists of three operations: meltirig and conditioning in platinum, vacuum-transferring through either platinum or tantalum, and casting into aluminum split molds. Currently, fused $\mathrm{CaCl}_{2}$ is prepared as follows: $5.5 \mathrm{~kg}$ of undried $\mathrm{CaCl}_{2}$ are fed into a platinum crucible in a furnace preheated to $350^{\circ} \mathrm{C}$. Argon gas is flushed over the salt as it melts. Once the salt is molten, $\mathrm{HCl}$ is sparged into the salt for $\sim 30$ minutes to dehydrate the salt and convert oxide impurities to chlorides. The salt is then sparged with argon to purge the system of $\mathrm{HCl}$, vacuum-transferred through a heated $1 / 2$-inch-o.d. platinum tube, and cast in split aluminum molds. The off gas line from this : ystem is kept free of condensed water and all off gas is routed through caustic scrubbers for neutralization prior to venting to the atmosphere. The total preparation time from lgading the loose salt into the furnace to casting the molten salt is approximately one hour.

Table IV shows that fused and cast salt has equivalent quality to pressed salt. Figures 11 and 12 show typical fused salts ready for use. To date, most of our efforts have involved comparing the performance of fused and pressed $\mathrm{CaCl}_{2}$ in the DOR process. We collected the data in Table $\mathrm{V}$ from 57 difference batches of foundrygrade $\mathrm{PuO}_{2}$. 


\begin{tabular}{|c|c|c|}
\hline \multicolumn{2}{|c|}{$\begin{array}{l}\text { TABLE IV. Semi-Quantitative } \\
\text { Fused and Pressed } \mathrm{CaC}_{2}\end{array}$} & \multirow{2}{*}{$\begin{array}{l}\text { Analyses fo } \\
\text { Fused } \mathrm{CaCl}_{2} \\
\text { (ppm or } \mathrm{wt}^{2} \% \text { ) }\end{array}$} \\
\hline Impurity & $\begin{array}{l}\text { Pressed } \mathrm{CaCl}_{2} \\
\text { (ppni or wt\%) }\end{array}$ & \\
\hline$\overline{\mathrm{CaO}}$ & 0.10 wt\% & 0.09 wt $\%$ \\
\hline $\mathrm{H}_{2} \mathrm{O}$ & 0.3 wt $\%$ & $0.3 w t \%$ \\
\hline Al & $<60$ & $<\mathbf{8 0}$ \\
\hline B & $5-100$ & $3-100$ \\
\hline $\mathbf{B a}$ & $<5$ & $<10$ \\
\hline $\mathrm{Be}$ & $<1$ & $<1$ \\
\hline $\mathbf{B i}$ & $<4$ & $<4$ \\
\hline $\mathrm{CO}_{3}$ & $<10$ & $<10$ \\
\hline Cd & $<4$ & $<4$ \\
\hline $\mathrm{Ce}$ & $<100$ & $<100$ \\
\hline Co & $<4$ & $<4$ \\
\hline $\mathrm{Cr}$ & $<4$ & $<4$ \\
\hline $\mathrm{Cu}$ & $<10$ & $<10$ \\
\hline $\mathbf{E r}$ & $<40$ & $<40$ \\
\hline $\mathbf{G g}$ & $<100$ & $<100$ \\
\hline Ge & $<4$ & $<4$ \\
\hline Hf & $<120$ & $<100$ \\
\hline In & $<4$ & $<4$ \\
\hline $\mathbf{K}$ & $600-25000$ & $600-25000$ \\
\hline $\mathbf{L a}$ & $<10$ & $<10$ \\
\hline $\mathbf{L i}$ & $<300$ & $<500$ \\
\hline $\mathbf{M g}$ & $<500$ & $<500$ \\
\hline $\mathbf{M n}$ & $<1$ & $<1$ \\
\hline Mo & $<4$ & $<10$ \\
\hline $\mathbf{N a}$ & $60-8500$ & $60-8500$ \\
\hline $\mathbf{N b}$ & $<4$ & $<10$ \\
\hline $\mathrm{Ni}$ & $<4$ & $<10$ \\
\hline Total oxygen & $0.55 w t \%$ & $0.45 w t \%$ \\
\hline $\mathbf{P}$ & $<120$ & $<120$ \\
\hline $\mathbf{P b}$ & $<4$ & $<4$ \\
\hline $\mathrm{Pt}$ & - & $<10$ \\
\hline $\mathbf{R b}$ & $<300$ & $<120$ \\
\hline $\mathbf{R e}$ & $<40$ & $<\mathbf{4 0}$ \\
\hline $\mathbf{S i}$ & $<100$ & $<250$ \\
\hline Sn & $<4$ & $<4$ \\
\hline $\mathbf{S r}$ & $100-10000$ & $100-10000$ \\
\hline $\mathrm{Ta}$ & $<100$ & $<100$ \\
\hline $\mathbf{T i}$ & $<4$ & $<4$ \\
\hline $\mathbf{V}$ & $<4$ & $<4$ \\
\hline $\mathbf{W}$ & $<360$ & $<100$ \\
\hline $\mathbf{Y}$ & $<4$ & $<4$ \\
\hline Zn & $<60$ & $<100$ \\
\hline $\mathrm{Zr}$ & $<12$ & $<12$ \\
\hline
\end{tabular}

The data in Table $\mathrm{V}$ indicate that fused $\mathrm{CaCl}_{2}$ ve forms at least as well as pressed salt in overall process recoveries and may reduce rerun frequency. These data helped justify converting from pressed $\mathrm{CaCl}_{2}$ to fused
$\mathrm{CaCl}_{2}$ in our pyrochemical operations. We had been using predried $\mathrm{CaCl}_{2}$ (scheduled for pressing) as feed for fusing, but planned facilities upgrades have shut down our drying iurnaces for an extended time. Because of this shutdown, we have had to fuse undried or asreceived $\mathrm{CaCl}_{2}$. Table VI compares DOR performance of fused, undried $\mathrm{CaCl}_{2}$ and fused, predried $\mathrm{CaCl}$.

These data indicate that with proper prep..ation. undried $\mathrm{CaCl}_{2}$ may be fused directly, without cornpromising either its quality or performance in DOR.

We are continuing to develop the fusing and casting procedure. Efforts in the area of $\mathrm{CaCl}_{2}$ conditioning include determining the minimum amount of $\mathrm{HCl}$ necessary to produce a salt with an acceptable total oxygen content $(<0.4 \mathrm{wt} \%)$. Tests have included flushing $\mathrm{HCl}$ gas over the surface of the salt. $\mathrm{HCl}$ sparging in the salt, and using an argon flush or sparge only. Results indicate that any of these procedures produces acceptable salts.

Figure 13 is a schematic of our transfer tube construction and Fig. 14 is a photograph of an actual device. We are wrapping the tubes with commercially available high-wattage heat tape with operating temperatures around $850^{\circ} \mathrm{C}$. These tapes are not compatible with metal surfaces nor can the tape overlap itself without developing an electrical short. We eliminate these problems by using a ceramic isolation sleeve to prevent tape contact with the metal tubing and by wrapping the tape carefully. These precautions and good insulation are necessary to heat the region of the transfer tube between the hot furnace and the casting mold to over $800^{\circ} \mathrm{C}$.

\section{ACKNOWLEDGMENTS}

All solvent salt production, most process and equipment development, optimization, and new concept implementation occur in a nonradioactive facility, which also serves as a training ground for MST-13 employees, providing glovebox, R\&D, production, and truubleshooting experience.

Individuals who helped develop the facility over the past three years include J. A. McNeese, S. A. Apgar, P. C. Lopez, W. K. Drennon, D. A. Hutchins, M. J. Chavez, D. W. Anderson, J. J. Lovato, J. J. Simpson, R. E. Mascarenas, M. D. Ferran, E. D. McCormick, J. Y. Coulter, C. E. C. Rense, and F. A Siephens. University summer students who have contributed include A. E. Buchholtz, K. J. Partin, L. A. Brockway, M. M. Moy, J. C. Kammer, and A. J. Figel. We would also like to acknowiedge our analytical chemistry group (CHM-1), whose personnel performed thousands of analyses on hundreds of samples. Without their timely response, the salt production and handling techniques we use today would still be in development. 


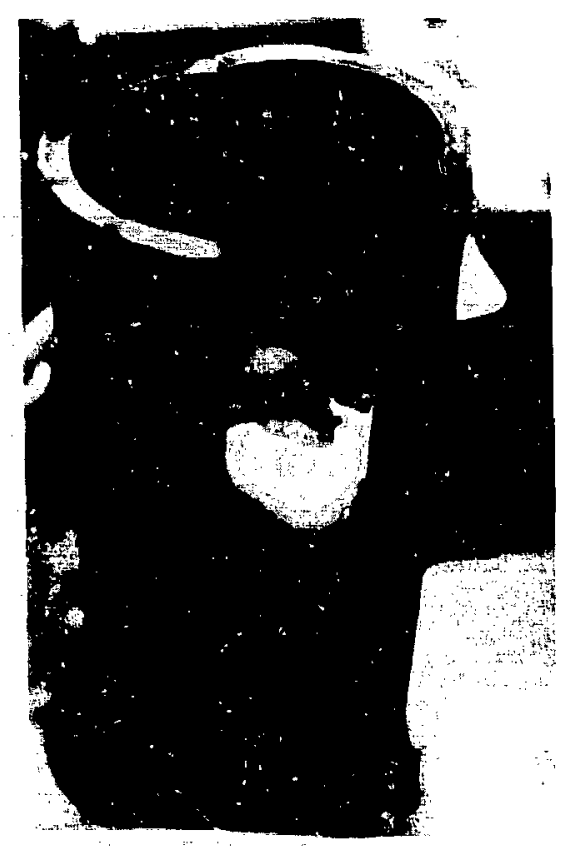

Fig. 11. Fused $\mathrm{CaCl}_{2}$ in an aluminum. split mold.

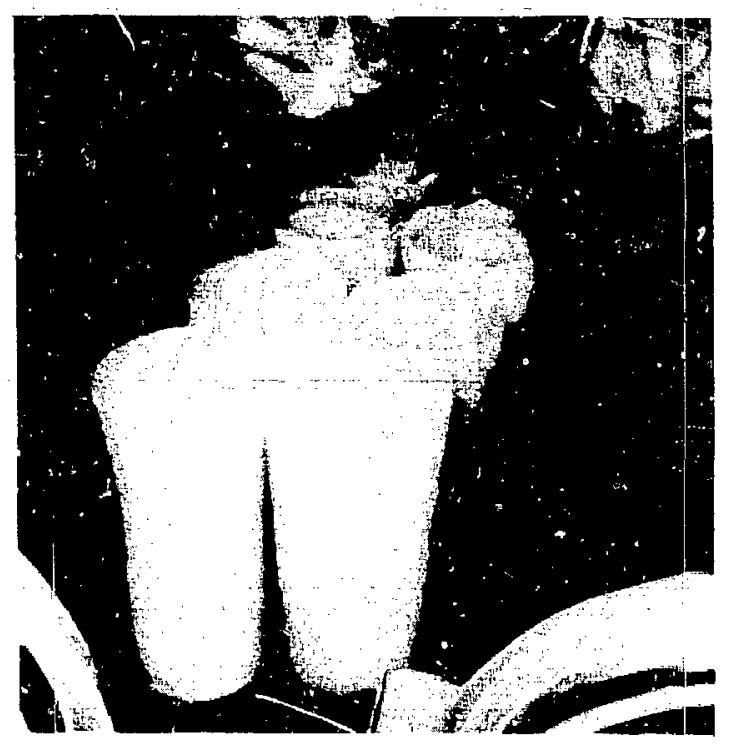

Fig. :2. Fused $\mathrm{CaCl}_{2}$ ready for packaging in an inert glovebox. 


\begin{tabular}{lccc}
\hline TABLE V. Comparison of Pressed $\mathrm{CaCl}_{2}$ and Fused $\mathrm{CaCl}_{3}$ in DOR \\
\hline Salt Type & DOR & Rerun Frequency & Overall Pu Recovery \\
Runs & $(\%)$ & $(\%)$ \\
\hline Fused & 397 & 20 & 93.7 \\
\hline
\end{tabular}

A rerun occurs through equipment failure or through unacceptable metal recoveries.

TABLE VI. Comparison of Undried and Predried Fused Salts in DOR

\begin{tabular}{lcccc}
\hline Salt Type & $\begin{array}{c}\text { Total Oxygen } \\
(w t \%)\end{array}$ & $\begin{array}{c}\text { DOR } \\
\text { Runs }\end{array}$ & $\begin{array}{c}\text { Rerun Frequency } \\
(\%)\end{array}$ & $\begin{array}{c}\text { Overall Pu Recovery } \\
(\%)\end{array}$ \\
\hline Undried, fused & $\mathbf{0 . 3 4}$ & 121 & 11.6 & 94.3 \\
Predried, fused & 0.34 & 356 & 11.0 & 94.5 \\
\hline \hline
\end{tabular}

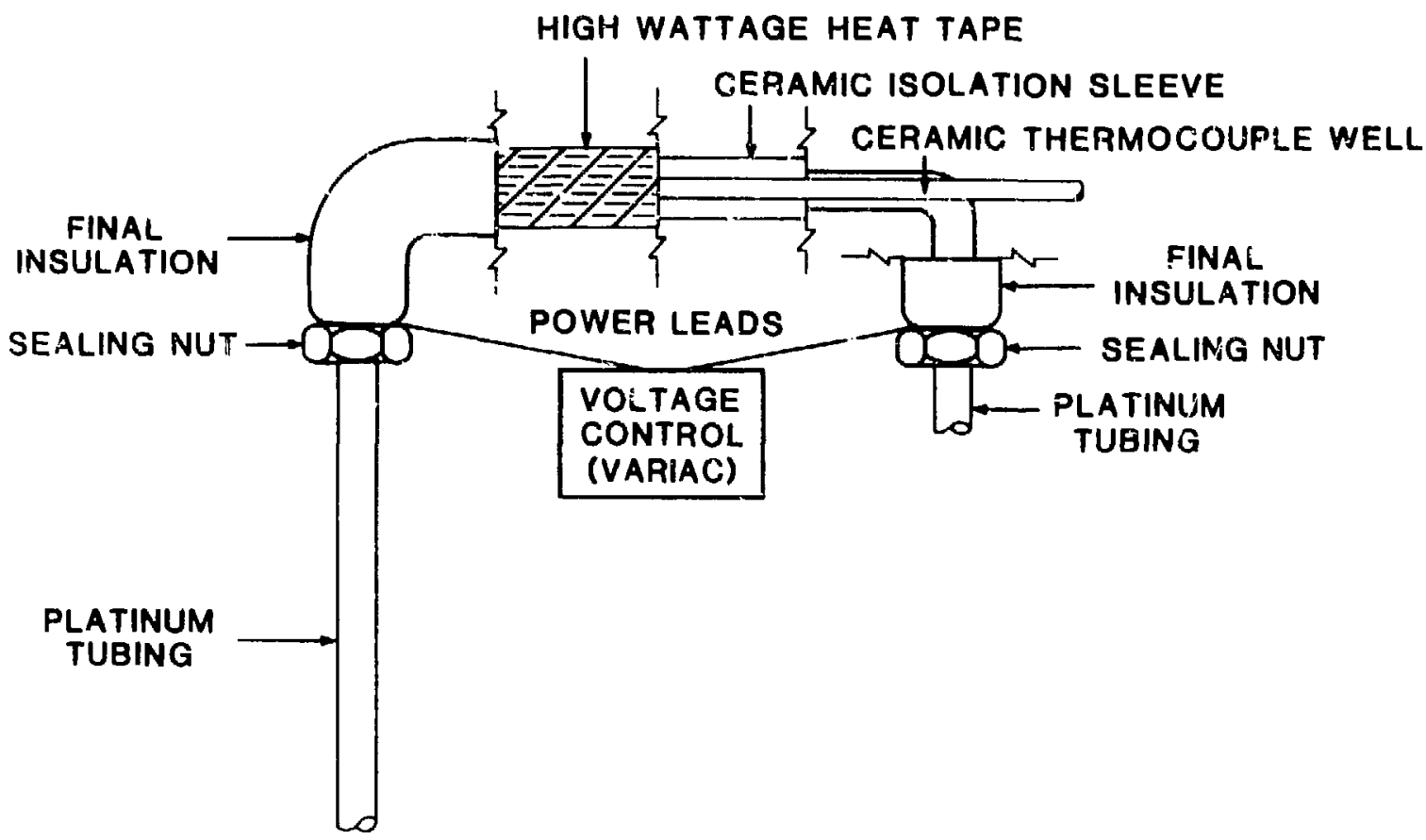

Fig. 13. Schematic of transfer tube for vacuum-transfer of molten salt. 


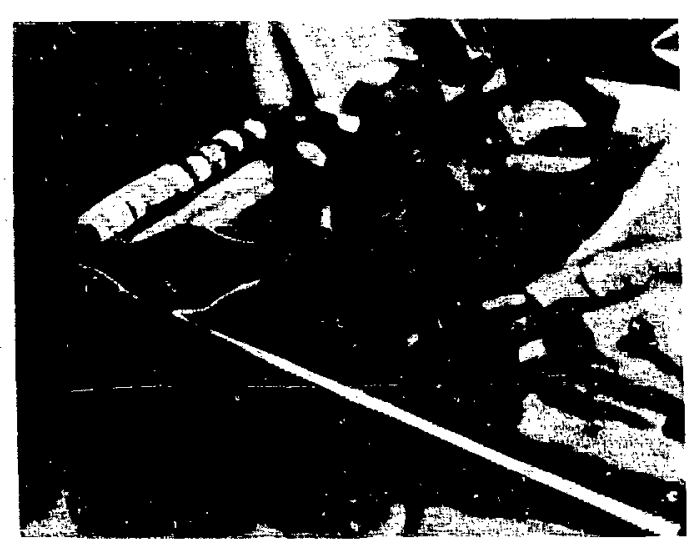

Fig. 14. Platinum transfer tube for casting $\mathrm{CaCl}_{2}$. The tube is shown with an attachment used to seal against the split mold.

\section{REFERENCES}

I. D. C. Christensen and L. J. Mullins, “Present Status of Plutonium Metal Production and Purification atLaboratory report LA-9674-MS (June 1983).

2. L. J. Mullins, D. C. Christensen, and B. R. Babcock, "Fused Salt Processing of Impure Plutonium Dioxide to High-Purity Plutoniurn Metal." Los Alamos National Laboratory report LA-9154-MS (January 1982).

3. R. D. Baker, "Pieparation of Plutonium Metal by the Bomb Method." Los Alamos Scientific L'boratery report LA-473 (May 1946).

4. J. M. Cleveland, The Chemistry of Plutonium (Gordon and Breach Science Publishers, New York. 1970).

5. L. J. Mullins and C. L. Foxx. "Direct Reduction of ${ }^{238} \mathrm{PuO}_{2}$ and ${ }^{239} \mathrm{PuO}_{2}$ to Metal," Los Alamos National Laboratory report LA-9073 (February 1982).

6. J. B. Knighton. R. G. Auge, and J. W. Berry, "Molten Salt Extraction of Americium from Molten Plutonium Metal," Rockwell International report RFP-2365 (March 1976).

7. L. J. Mullins and J. A. Leary, "Fused-Salt Electrorefining of Molten Plutonium and Its Alloys by the LAMEX Process," IEC Proc. Design Dev. Vol 4, 394 (October 1965).
8. L. J. Mullins and A. N. Morgan, "A Review of Operating Experience at the Los Alamos Plutonium Electrorefining Facility, 1963-1977," Los Alamos National Laboratory report LA-8943 (December 1981).

9. L. .' Mullins, A. N. Morgan, S. A. Apgar, and D. C. Christensen, "Six-Kilogram Scale Electrorefining of Plutonium Metal," Los Alamos National Laboratory report LA-9469-MS (September 1982).

10. K. W Fife, D. F. Bowersox, and E.D. McCormick, "Comparison of Phosgene, Chlorine, and Hydrogen Chloride as Reagents for Converting Molten $\mathrm{CaO}$. $\mathrm{CaCl}_{2}$ to $\mathrm{CaCl}_{2}$," Los Alamos National Laboratory report LA-10523-MS (October 1985).

11. D. C. Christensen and J. A. Rayburn, "Pyrochennical Recovery of Plutonium Fluoride Reduction Slag," Los Alamos National Laboratory report LA-9655-MS (July 1983).

12. K. W. Fife, D. C. Christensen, and J. D. Williams, "Plutonium and Americium Separation from Molten Salt Extraction Waste Salts," Los Alamos National Laboratory document LAUR-84-1360 (December 1984).

13. K. W. Fife, "Recovery of Plutonium from MSE iVaste Salts by Molten Salt Electrochemical Techniques." Los Alamos National Laboratory sucument LA-UR-85-156 (May 1985).

14. D. C. Christensen and L. J. Mullins, "Salt Stripping, A Pyrochemical Approach to the Recovery of Plutonium clectrorefining Salt Residues," Los Aiamos National Laboratory report LA-9464-MS (October 1982).

15. j. A. McNeese, D. F. Bowersox, and D. C. Christensen, "Recovery of Plutonium by Pyroredox Processing," Los Alamos National Laboratory report LA-10457 (September 1985).

16. D. Inman and D. G. Lovering, Ionic Liquids (Plenum Press, New York, 1981). 